\title{
A PEDIGREE OF MENTAL DEFECT SHOWING SEX-LINKAGE
}

\author{
BY
}

\section{J. PURDON MARTIN and JULIA BELL}

(From the National Hospital, Queen Square, London)

(ReCEIVEd 7TH OCTOBER, 1943)

THE following history of imbecility in eleven males of two generations was brought to our notice some years ago when a child aged eighteen months, now indicated as V 54 on the adjoining pedigree chart, was brought to the outpatient department at the National Hospital by his mother who suspected that he was showing the signs of mental deficiency which she had already seen develop in some of the sons of her sisters; she was further aware of the condition in her cousins IV 13 and 14 . The mother of the patient, IV 22, was intelligent and was much concerned about the family history; she provided at that time complete information regarding her own branch of the family and obtained the collaboration of her aunt, III 1, in working out the extended pedigree, including the three defective brothers V 16, 18, and 19. At this time one of us (J.P.M.) visited many of the descendants of III 4; he noted the undoubted intelligence of the seven daughters of III 4 and examined their defective sons in institutions or in their homes.

More recently we have been able to get in touch with some of the descendants of III 2 and to see the three imbecile sons of IV 3 . This side of the pedigree has been much extended since the original history was given by III 1 , and to some extent modified. Our information was provided by IV 3 and 4 , but they did not welcome inquiry and discouraged our attempt to see the only other living member of the sibship IV 1-11, or to call upon V 13. IV 3 was uncertain about some details regarding the sex and number of her nieces and nephews and we did not feel assured that she would know if, for example, IV 2 , or IV 9 had had defective sons or grandsons. Two of the twins of IV 2 had died in infancy, but IV 3 did not know whether they had been boys or girls. It is illustrative of the secretiveness of this branch of the family that at the time of the earlier pedigree III 1 was unaware that she had any grandchildren through her daughter IV 2, or that her son IV 1 had more than one child. IV 3 was fiercely protective in her attitude to her imbecile sons and resentful that, when found as small boys wandering in Hyde Park, they had been placed in an institution; she believed that they could have helped her at home and contributed to the family earnings; she suggested that their lack of mental development was due to lack of teaching, though actually it had been found impossible to teach them in special schools. Had we not seen those sons their mother would have given us an entirely erroneous impression of them; she attributed their condition to the shock to her, when she was carrying V 16, due to V 15 falling from a window through 19 feet to the ground. IV 3 was quite unaware that any other cases of mental defect had occurred in the family.

In the present inquiry IV 22 has again been helpful, and she and her eldest sister IV 16 have brought the history of their section of the family up to date.

We have examined the three defective sons of IV 3, and have re-examined all but one (V 51) of the six defective grandsons of III 4 . All these eight and also V 51 show a severe degree of dementia, their mental ages being between two and four years. In seven of them the dementia is simple, in the other two (V 48 and 50) it is complicated by pronounced psychotic traits. No peculiar features, either mental or physical, have been recognized which would serve to distinguish the disease which afflicts this family from other forms of dementia. For the most part their affective state is normal: they are goodtempered, not abnormally moody, docile, and interested in their environment. It will be evident that with such a temperament they are not antisocial, but are able to fit in a limited way into society; thus V 51 and V 54 still live at home and the latter obtains simple employment; V 38 and 41, though now in an institution, lived at home till recently; and V 16 lived at home up to the age of 16. They have been brought up by intelligent mothers and are clean in their habits, and are in general able to perform such duties as are within the mental capacity of a child of three or four years. They do not, however, show the activity, initiative, and imitativeness of a normal child of that age. Their vocabulary is extremely limited; in fact most of them are almost inarticulate. They can answer very simple questions by " yes" or " no"; they can say their own names (not always correctly) and the names of the most common objects; none of them can make a sentence; V 54 when asked what work he did (carrying coal) after long hesitation and obvious agitation uttered the single word "black." Of the two psychotic members of the group, V 50 is of paranoid type-suspicious, pugnacious, resentful, and destructive; V 48 is markedly schizoid, and has now reached a state of almost complete mental detachment from his surroundings, 


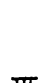
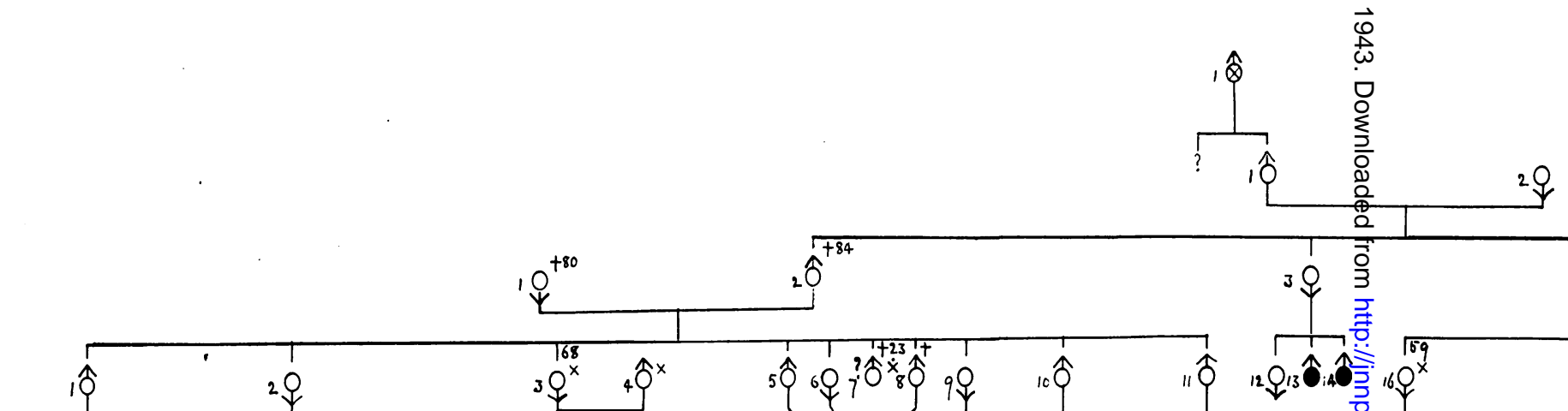

- Imbecility

Omental deficiency X SEEN




with mutism and unceasing stereotyped movements. This patient, in contrast to all the others, is of a delicate physical type.

Physically the affected members are not abnormal. They are in general of sturdy build, but they do not show any distinctiveness in shape of head or face, colour of eyes, dentition, bodily proportions, or other observed physical character. They show no abnormal physical signs in their nervous systems. They began to walk about the age of two years, and their gaits are normal. Their sexual development appears to be normal.

Five of these patients are now over thirty years of age and there is no evidence that the disease is progressive. It is true that one individual (V 48) has shown marked psychotic deterioration at the age of puberty, but he is in various ways exceptional. The mental and physical states of the others are stationary. This suggests that the disease is essentially a defect of development, which remains unchanged throughout life. In this way it differs from other hereditary cerebral diseases such as Huntington's chorea, tuberose sclerosis, cerebromacular degeneration (Tay and Sachs), and the Pelizaeus-Merzbacher disease, as well as from the hereditary ataxias and the myopathies. Rather is it analogous to hereditary defects of bodily development such as aniridia and albinism.

During the seventeen years that this family has been under observation no opportunity has occurred of examining the brain of an affected subject. The complete absence in the affected individuals of disturbances in the motor, somatic sensory and special sensory functions suggests that the cerebral defect is chiefly, if not entirely, in the pre-frontal portions of the cerebral hemispheres, and the very imperfect development of the speech function is in keeping with this suggestion.

The following are brief notes of the affected individuals whom we have examined :-

V 16.-Now 37. Has been in institutions since the age of 16. Mental age by different tests $2 \cdot 7-4$ years. Conforms to the general description given above; cannot count: does not know any letters. "Intensely curious and follows the nurses about, watching their doings." Affectionate and sociable. Hoards rubbish. Physically, long trunk relative to length of legs.

V 18.- Now 33. In institutions since age of 13. Mental age 3 years. Conforms to general description. Not aggressive, sociable, helps a little in the ward. Cannot repeat two numbers. Physical proportions, normal. Does not speak distinctly.

V 19.-Now 31. In institutions since age of 9. Normal age about 3 years. Cannot say whether he is a boy or a girl. Very shy. Not so good-tempered as his brothers; impulsive and occasionally violent. Physically similar to V 16.

V 38.- Now 36. Lived at home until his father died about a year ago. Mental age 4.4 years. Good-tempered; answers in single words. His mother said he was capable of helping in the house by bringing in coal, etc., sturdy build. Rather long trunk relative to legs.

V 41.-Now 27. Lived at home till one year ago. Mental age 3.5 years, but his mother says he went to a school till he was 11. Affectionate; sociable; wellbehaved. Mother recognizes that he is not capable of as much as his brother (V 38).

V 48.- Now 17. Lived at home till age of 14 . Low- grade imbecile with katatonic psychotic traits. Is unemployable, wet, and dirty. Has shown gradual mental deterioration since admission to an institution. Delicate physical type. Does not resemble any of his cousins.

V 50.-Now 30. In institution since age of 8 . Mental age cannot be tested because of patient's attitude. Does not answer any questions, suspicious, resistive, spiteful, destructive. Sturdy physical build. Cephalic index 85 . Notes say he learned to walk at $2 \frac{1}{2}$ years and talked at the age of 3 .

V 51.- Now about 27. Lives at home. Mentally and physically conforms to general description.

V 54.- Now 18. Lives at home. Used to go round with milkman and take milk bottles to doors. Now helps a man to deliver coal in the street. Mental age about 3 years. Answers in single words. Goodtempered; very shy. Physically taller than his affected cousins; strong build; big face and jaw. In features takes after his mother, but in him her features are exaggerated.

The two larger divisions of this family are derived from III 2 and III 4, believed to be normal; both these brothers have large families and III 2 lived to be 84 ; III 4 was a bricklayer who died from gastritis at the age of 51 . Of the siblings of III 2 and 4, one brother III 5 and his descendants are said to have been normal. III 3 appears to have been a woman of assertive character whose household was avoided by the daughters of III 4, and by IV 3 , not alone because of her defective sons who lived at home; she was said by III 1 to have been normal. The two sons of III 3 were well remembered by their cousins, IV 16 and 22, as severe cases of mental deficiency, conspicuous in the streets and frightening to little girls; we have been unable to discover the fate of these sons or to hear of any descendants of their sister IV 12, believed to have been normal.

The two main branches of this family never see one another; the descendants of III 4 appear to live under more comfortable conditions than those of III 2, but the same rather quick intelligence and efficiency in some respects, is suggested by IV 3 as is evident, accompanied perhaps by more self-control, in the daughters of III 4. IV 3, a heavily built woman, crippled by arthritis, is of a dominating type with a highly nervous temperament; her daughter, $\mathrm{V} 15$, is a dressmaker and if she seemed nervous and inarticulate in her home it must be remembered that she has always been held responsible there for the state of her imbecile brothers. IV 4, said that all his children, apart from the defective sons, had done well; V 14, in the Army, has four healthy children; V 13 is evidently intelligent; V 17 has three children of whom two have already won scholarships. V 12 died from diphtheria; two children under V 22, were premature and still-born. Less is known of IV 3's brothers and sisters. IV 8 was killed in the War of 1914-18. Four of the five living children of IV 11 are now serving in the Army; V 32, said to be very fat, is employed in a fish shop. We may safely assume with regard to this branch of the family that the children of III 2 and of IV 3 , and IV 11 are accurately described on the chart; 
information regarding the offspring of IV 1, 2, 9, and 10 may-or may not-be incomplete.

Our knowledge of the other main branch of the family is more satisfactory. Of the five children of IV 16, two are typical instances of the family disease; two normal sons are serving in the Army; V 42 is working in a hospital; she reached a fair standard at school and in a brief interview appeared to be normal, but her mother regards her as rather backward in that she can never calculate what change she ought to have when shopping. IV 17 had two daughters who won scholarships. V 43 is described as "backward"; she was educated in schools for the defective, and was unable to do the simplest arithmetic, but she has always lived at home and was able to look after her young brothers and sisters; she does not fall into the same category as the imbecile sons of the stock; this woman has lately married a man of mental equipment similar to her own. Of V 45-47 one was still-born, one was found dead in his cot one morning; all died before it was possible to make any note of their mental state. The only surviving son of IV 17 is the psychotic imbecile V 48 . IV 21 had one child, a " backward" daughter who works as a waitress in a restaurant; she is able to take orders and carry round trays, but cannot make out accounts, or do the simplest arithmetic. IV 22 asked to be, and was, sterilized in order to avoid the risk of having further defective children. IV 24 has two unusually clever children who have both won scholarships; her son V 55 died at 9 months from status lymphaticus. IV 18 and 19 died in early infancy.

I 1 was known to have died in an asylum, but no further particulars concerning him were available; we think his mental disturbance was probably one which came on late in life, and was quite unrelated to the defect in his descendants. II 1 is believed to have been normal; he died as the result of an accident in which he was thrown from a dogcart. II 2 occupies a key position in the pedigree, for if the defect here described is sex-linked she represents the probable means of its introduction into this family. Unfortunately little is known of her and nothing of her brothers and sisters.

Two rather serious doubts remain which concern the mental states of IV 7 and V 1 . III 1 reported that $\mathrm{V} 1$, who died from diphtheria aet. 7, had not been mentally normal; IV 3 , however, says that he attended the ordinary schools and was normal, running about and playing with other children until his fatal illness; when told that III 1 had reported otherwise, she said that this was because her mother had never liked the child's mother! No other member seen by us had any personal recollection of this boy; the account given by IV 3 certainly suggests that he was normal. IV 7 was classified as mentally normal by his mother III 1 , and by IV 3 and 4; IV 22 said he was illiterate and, in her opinion, probably not mentally normal; IV 16 said he never went to school and was unable to speak clearly; she remembered seeing him about in the streets and thought he was certainly not normal, IV 3 and 4, on the other hand, were in closer touch with him; they say he was always at work, as a labourer, and was employed by the Borough Council. IV 3 helped to nurse him when he became ill and very emaciated from tuberculous disease; she was unwilling to think he was not perfectly normal. It may be that he suffered from some lack of development, but it cannot have been of the same degree as that shown by the defective members of the family whom we have examined, and the condition may not have been of genetic origin.

The interpretation of this family history from the genetic standpoint is not quite straightforward. All cases of gross mental defect occur in males who are sons of normal females of the stock; if we assume-as seems likely, despite some conflicting evidence-that IV 7 and V 1 do not fall into the same category as their imbecile cousins, we cannot escape the conclusion that a sex-linked gene is in operation. The simplest explanation to offer seems to be that the manifestation of a sex-linked gene, introduced by the carrier II 2, was suppressed by the presence of some controlling factor in III 2 . and III 4 ; III 3 proyides evidence of its potentiality in her defective sons. III 2 and III 4 were believed to be normal. On this hypothesis all the daughters of III 2 and III 4 should be potential carriers of the defect, liable to have sons half of whom would exhibit the defect, and daughters, half of whom would be catriers. The pedigree is not inconsistent with this hypothesis, though we should like to have more first-hand information concerning the families of IV 2 and IV 9, and to know particularly whether the deaths in infancy among the twins of IV 2 occurred in boys or in girls. With regard to the milder form of deficiency, exhibited by the females V 42 and 53, we can only record the facts. We would remind the reader, however, that occasionally genes appear to be incompletely recessive, in that they may manifest to a less severe degree in heterozygotes of the stock; this pedigree may well provide an example of such a phenomenon.

If this interpretation is correct the unaffected males of generation $\mathrm{V}$ should not be liable to transmit the defect. In view, however, of the apparent suppression of the disease demonstrated in III 2 and III 4, we cannot be sure that such examples may not occur again.

It is very rare to find such an hereditary history as this in cases of mental defect; the only example known to us in the least comparable is that published by Ash (1922) and later expanded and described by Fraser Roberts (1937) under the title "Sexlinked microphthalmia sometimes associated with mental deficiency." Of six males affected with microphthalmia whom Roberts personally examined, four were in some degree mentally deficient. "The blind males may be of normal mentality or may exhibit any grade of mental deficiency from feeblemindedness to profound idiocy." In the family group referred to there was no mental deficiency except in association with the blindness. Penrose (1938), in his investigation of 1280 cases of mental 
defect, found insufficient evidence to support the view that sex-linked genes played a significant part in the etiology of mental defect-a testimony to the rarity of such a history as the one now described.

\section{Summary}

A family is described in which, in eleven known instances, mentally deficient sons have been born to normally intelligent mothers; the affected individuals show a severe degree of dementia, their mental ages being between 2 and 4 years; the affective state in most of them is normal. In spite of certain difficulties, it is believed that the mental defect is due to a sex-linked recessive gene.

In two known instances relatively slight mental deficiency has occurred in females of the family, and it is suggested that in these two the causal gene was incompletely recessive.
All but one of the mothers concerned were the daughters of two brothers, the other being their sister; these two brothers are said to have been normal and the hypothesis is put forward that some controlling factor caused suppression of the disease in them without affecting therr liability to transmit it.

We wish to express our thanks to Dr. R. M. Stewart, Dr. T. Lindsay, and Dr. K. C. L. Paddle who have permitted us to examine patients under their care and have given us every assistance.

\section{REFERENCES}

Ash, W. M. (1922). Brit med. J., 1, 558.

Penrose, L. S. (1938). A Clinical and Genetic Study of 1280 cases of Mental Defect. London.

Roberts, J. A. F. (1937). Brit. med. J., 11, 1213. 